\title{
AVALIAÇÃO DOS ÓBITOS OCORRIDOS NO HOSPITAL UNIVERSITÁRIO DA UNIVERSIDADE FEDERAL DE SANTA CATARINA (HU/UFSC)
}

Rachel Duarte Moritz*, Guilherme Beduschi, Fernando Osni Machado

Trabalho realizado no Hospital Universitário Professor Polydoro Ernani de São Thiago da Universidade Federal de Santa Catarina (HU/UFSC), Florianópolis, SC

*Correspondência: Rua João Paulo, 1929. João Paulo CEP 88030-300 Florianópolis, SC Tel: (048) 9972-8800 rachel@hu.ufsc.br

\begin{abstract}
RESUMO
ОвJetivo. Avaliar os óbitos ocorridos no HU/UFSC. Comparar o perfil dos pacientes que morreram nas enfermarias com o daqueles que morreram na UTI. Verificar se os óbitos foram considerados esperados (E) e não evitáveis (NE). Constatar se houve recusa/suspensão de terapêutica (RST) precedendo a morte.

Métodos. Obtivemos dados por meio de ficha elaborada pela Comissão de Óbito Hospitalar ( $\mathrm{COH})$, na qual constavam os aspectos demográficos, clinicos e terapêuticos dos pacientes e a avaliação da $\mathrm{COH}$ sobre a expectativa/evitabilidade dos óbitos.

Resultados. Analisamos os dados dos 326 pacientes com mais de I4 anos, que morreram entre julho/2004 e dezembro/ 2005. Desses, I 28 morreram na UTI (GI) e 198 nas enfermarias (G2). A RST precedeu 38,2\% dos óbitos no GI e $2 \%$ no $\mathrm{G} 2$ ( $p<0,00 \mathrm{I})$. As principais terapêuticas recusadas/suspensas foram drogas vasoativas e antibióticos. No $\mathrm{GI}$ cerca de $20 \%$ das mortes foi classificada como E/NE. No G2 considerou-se $5 \%$ das mortes evitáveis e $6,5 \%$ não esperadas $(p<0,001$ ). Os pacientes do $\mathrm{GI}$ eram mais jovens e do sexo masculino $(\mathrm{p}<0,005)$. A ordem de não reanimar constava em $48,4 \%$ dos prontuários do $\mathrm{G} 2$ e em $6,3 \%$ do $\mathrm{GI}(\mathrm{p}<0,001)$. Manobras de reanimação cardiorrespiratória (RCR) ocorreram em 23,4\% no $\mathrm{Gl}$ e em $5,5 \%$ no $\mathrm{G} 2(\mathrm{p}<0,001)$.

Conclusão. Na UTI, os pacientes que morreram eram mais jovens, receberam mais DVA e os óbitos foram mais freqüentemente precedidos da RST. Houve reanimação cardiorrespiratória em 5\% das PCR nas enfermarias onde se constatou ordem de não reanimar em $48 \%$ dos prontuários. Poucos óbitos foram considerados E/NE. Não houve indícios de erro profissional ou institucional nesses óbitos.
\end{abstract}

UnItermos: Morte. Ética. Terapia fútil. Recusa. Tratamento

\section{INTRODUÇÃO}

A partir do século passado o desenvolvimento tecnológico modificou o estilo e a perspectiva de vida do ser humano, ${ }^{1,2}$. envelhecimento trouxe profundas modificações na morbimortalidade da população. As doenças crônico-degenerativas superaram as doenças infecto-contagiosas como os principais causa de morte 3 . Concomitantemente, os hospitais ganharam novas tecnologias no campo do tratamento e do suporte de vida. As Unidades de Terapia Intensiva (UTIs) surgiram como opção no tratamento do paciente gravemente enfermo. As instituições de saúde aumentaram em número e firmaram-se, na cultura ocidental, como referência para o tratamento de doenças. Como um corolário, a maioria dos óbitos passou a ocorrer nessas instituiçõos ${ }^{2,-46,8}$. Cita-se como exemplo os óbitos ocorridos na cidade de Florianópolis, no ano de 2003. Nesse ano, ocorreram I.708 óbitos: I.25I em hospitais $(73,2 \%)^{9}$ e, mais especificamente, 328 (19,2\%) no Hospital Universitário Polydoro Ernani de São Thiago da Universidade Federal de Santa Catarina (HU/UFSC).

Tendo em vista o relatado, foi constatada uma crescente necessidade de que seja desenvolvido um controle da qualidade dos serviços prestados pelos hospitais. Tornou-se necessário que o tratamento do paciente considerado terminal seja repensado, devendo ser priorizado o seu conforto clínico e psíquico. Cada vez mais tem sido discutida a necessidade do desestímulo à obstinação terapêutica, definida como o prolongamento do processo de morrer. Essa obstinação gera uma questão ético-social pois, além de acarretar um sofrimento desnecessário ao paciente e aos seus familiares, aumenta o consumo dos escassos recursos reservados à saúde" '. Levando em consideração essa nova realidade, o médico deve estar apto a reconhecer as suas limitações e deve considerar a importância da sua aceitação quanto a suspensão ou recusa de tratamentos (RST) considerados fúteis ou inúteis.

Diante do exposto, propôs-se este trabalho que visou avaliar os óbitos ocorridos no HU/UFSC no período de julho de 2004 a dezembro de 2005 e comparar o perfil dos pacientes que morreram nas enfermarias com o daqueles que morreram na UTI. Secundariamente, objetivou-se verificar se os óbitos foram considerados esperados e não evitáveis e constatar se houve recusa ou suspensão de terapêutica precedendo a morte. 


\section{Métodos}

Este foi um estudo de coorte retrospectivo, não controlado, com abordagem qualitativa e quantitativa, que foi realizado no HU/UFSC, após a aprovação pelo Comitê de Ética em Pesquisa com Seres Humanos da UFSC n³75/05.

Foram incluídos no estudo todos os pacientes internados no HU/ UFSC, com idade superior a 14 anos, que faleceram no período de julho de 2004 a dezembro de 2005. Foram excluídos todos os pacientes que faleceram no setor de emergência ou os que chegaram ao hospital vítimas de parada cardiorrespiratória (PCR).

Os dados foram colhidos por meio do protocolo de investigação de óbitos hospitalares, que foi desenvolvido pelos membros da Comissão de Óbito Hospitalar (COH-HU). Os membros da $\mathrm{COH}-\mathrm{HU}$ foram consultados e permitiram a utilização desse protocolo. Foram avaliados os dados referentes aos aspectos demográficos, clínicos e terapêuticos dos pacientes, assim como a causa do óbito conforme o atestado de óbito. Foi também observado se a morte do paciente foi precedida da ordem de não-reanimação, em caso de PCR, ou da RST. Foi também anotada a avaliação qualitativa dos membros da $\mathrm{COH}$, que classificaram os óbitos como esperados ou não e como evitáveis ou não. A relação de pacientes que morreram no HU/UFSC foi obtida mensalmente por meio das estatísticas do sistema de informática desse hospital pelos membros da $\mathrm{COH}$. Foram então solicitados os prontuários que foram analisados. Os dados foram anotados no protocolo de investigação. Os casos controversos foram discutidos nas reuniões mensais da $\mathrm{COH}$. Ressalta-se que, para este trabalho, os autores tiveram acesso aos dados previamente obtidos pela $\mathrm{COH}$, sem pesquisa direta aos prontuários dos pacientes.

Seguindo-se a deliberação da Portaria do Ministério da Saúde №. 312 de 2 de maio de 2002, considerou-se como óbito hospitalar aquele que ocorreu após o paciente ter dado entrada com vida no hospital, independente do fato dos procedimentos administrativos relacionados à internação já terem sido realizados ou não. Óbito institucional foi o que ocorreu após 24 horas da internação do paciente.

No estudo estatístico utilizou-se, para as variáveis quantitativas o teste $t$ de Student e para as variáveis qualitativas o teste Qui quadrado (c2), sendo considerado significante um $p<0,05$.

\section{Resultados}

No HU/UFSC existem 268 leitos de enfermarias clínicas e cirúrgicas e seis, leitos de UTI. No período do estudo internaram nesse hospital |4.346 enfermos, sendo constatada uma média de 797 internações/mês. Na UTI, no período estudado, foram verificadas 53 I internações. Foram avaliados os dados dos 326 pacientes, com mais de 14 anos, que estavam internados e que vieram a falecer. Constatou-se que, por decisão médica com aquiescência dos familiares, houve recusa ou suspensão de terapia em $16 \%$ dos casos. A ordem de não reanimar foi verificada em $32 \%$ dos prontuários, $13 \%$ dos óbitos foram considerados não-esperados e $9 \%$ evitáveis. A taxa de óbito hospitalar constatada foi de $3 \%$ e a taxa de óbito institucional foi de 2,13\%. Nas enfermarias, a taxa de óbito foi de 3,8\% e na UTI foi de 25,9\%. Dos 326 óbitos, 128 ocorreram na UTI e 198 nas enfermarias (26 nas enfermarias cirúrgicas e 168 nas enfermarias clínicas).
Na Tabela I, são demonstrados os aspectos clínicos e demográicos dos pacientes que morreram. Ressalta-se que I4 (6,25\%) óbitos ocorridos nas enfermarias eram de pacientes que haviam recebido alta da UTI. Dos quatro pacientes das enfermarias, cujas mortes foram precedidas da RST, três haviam recebido alta da UTI. Quanto aos pacientes que faleceram na UTI, a média de idade daqueles para os quais houve RST precedendo o óbito $(n=49)$ foi de 58 , I anos e a média de idade daqueles que receberam terapia plena até o momento da morte foi de 56,8 anos (NS). Na Tabela 2 são enumeradas as principais terapias suspensas ou recusadas que precederam os óbitos.

Os óbitos não esperados contabilizaram 26 casos (20,3\%) na UTI e 13 casos (6,5\%) nas enfermarias $(p<0,00 \mathrm{I})$. Os óbitos considerados evitáveis totalizaram 29 (8,9\%). Desses, 19 (5\%) ocorreram na UTI e 10 (3\%) nas enfermarias. As diferenças observadas quanto à evitabilidade e expectativa dos óbitos nessas unidades foram estatisticamente significantes $(p=0,004)$. Na Tabela 3 são destacados os motivos que levaram os membros da $\mathrm{COH}$ a julgarem os óbitos como evitáveis.

\section{Discussão}

Neste estudo, que avaliou os óbitos ocorridos no HU/UFSC, no período de julho de 2004 a dezembro de 2005, constatou-se que as características clínicas e terapêuticas dos pacientes que morreram nas enfermarias foram diferentes das características dos pacientes que morreram na UTI. Goodlin et al. ${ }^{2}$ descreveram que pacientes que estavam apenas recebendo medidas de conforto tendiam a estar internados nas enfermarias, sem que thes fosse indicada internação na UTI. Esses pacientes apresentavam uma média de idade de 68,9 anos. Neste estudo, os pacientes que morreram na UTI ( $57 \pm$ I 8 anos) eram mais jovens do que aqueles internados nas enfermarias (70,4 \pm 17 anos). Esta diferença pode ser atribuída ao fato de que os pacientes mais velhos são acometidos mais freqüentemente por doenças terminais, inerentes a finitude do ser humano. Corrobora com essa afirmação a constatação de que em $48 \%$ dos prontuários dos pacientes internados nas enfermarias, havia, por escrito, a ordem de não reanimar. Apesar desses números parecerem altos para a realidade brasileira, estudos norte-americanos apontam índices mais elevados de ordem de nãoreanimação. Goodlin et al. ${ }^{2}$ relataram que $89 \%$ dos pacientes que faleceram no Veterans Affairs Hospital possuíam no seu prontuário a ordem de não ressuscitar. Fins et al. ${ }^{6}$ relatam que esse índice chegou a $70 \%$ no The New York Hospital. Deve ser lembrado que a clientela dos hospitais é diferente, principalmente em decorrência de fatores socioeconômicos.

Neste estudo, houve distribuição eqüitativa quanto ao sexo dos pacientes que morreram nas enfermarias e houve predominância do sexo masculino entre aqueles que morreram na UTI. Resultados diferentes foram apontados por Hall et al. ${ }^{12}$, que encontraram $53 \%$ de pacientes do sexo masculino nos 174 óbitos ocorridos em uma UTI canadense e por Toscani et al. ${ }^{4}$, que analisaram os óbitos ocorridos em enfermarias de hospitais italianos e apontaram um discreto predomínio do sexo feminino (53\%).

Constatou-se neste trabalho que os pacientes que morreram nas enfermarias, e que haviam recebido alta da UTI, eram vítimas de patologias consideradas irreversíveis. Foi considerado pelos médicos 


\begin{tabular}{|c|c|c|c|c|c|c|}
\hline \multirow[t]{2}{*}{$\begin{array}{l}\text { Variáveis clínicas } \\
\text { e demográficas }\end{array}$} & \multirow{2}{*}{\multicolumn{2}{|c|}{$\begin{array}{c}\text { Óbitos } \\
\text { na UTI (GI) } \\
n=I 28 \\
N\end{array}$}} & \multirow{2}{*}{\multicolumn{2}{|c|}{$\begin{array}{c}\text { Óbitos nas } \\
\text { enfermarias (G2) } \\
\mathrm{N}=198 \\
\%\end{array}$}} & \multirow{3}{*}{$\begin{array}{c}\text { Teste } \\
\mathbf{N} \\
\chi^{2}\end{array}$} & \multirow{3}{*}{$\begin{array}{c}\mathbf{P} \\
\% \\
0,004\end{array}$} \\
\hline & & & & & & \\
\hline $\begin{array}{l}\text { Sexo } \\
\text { Masculino } \\
\text { Feminino }\end{array}$ & $\begin{array}{l}87 \\
41\end{array}$ & $\begin{array}{l}68 \\
32\end{array}$ & $\begin{array}{l}102 \\
96\end{array}$ & $\begin{array}{l}52 \\
48\end{array}$ & & \\
\hline Uso drogas vasoativas & 97 & 75,7 & 15 & 7,5 & $\chi^{2}$ & $<0,001$ \\
\hline Terapiasuspensa/recusada & 49 & 38,2 & 4 & 2 & $\chi^{2}$ & $<0,001$ \\
\hline Ordem de não realizar RCP II & 8 & 6,3 & 96 & 48,4 & $\chi^{2}$ & $<0,001$ \\
\hline Manobras de RCP & 30 & 23,4 & II & 5,5 & $\chi^{2}$ & $<0,001$ \\
\hline Óbito durante o dia (7-19h) & 65 & 50,7 & 100 & 50,5 & $\chi^{2}$ & $\mathrm{NS}^{+}$ \\
\hline Média de idade em anos & 57,1 & & 70,4 & & & \\
\hline (Desvio padrão) & $( \pm 18)$ & & $( \pm 17)$ & & TStudent & $<0,001$ \\
\hline Tempo médio UTI em dias & 6,1 & & $10,5^{\S}$ & & TStudent & NS \\
\hline Escore APACHE II médio & 27,7 & & $25,5^{\prime \prime}$ & & TStudent & NS \\
\hline
\end{tabular}

intensivistas e explanado para os familiares dos pacientes que os mesmos não se beneficiariam com o tratamento intensivo. Pode-se inferir que essa conduta objetivou o maior conforto emocional dos enfermos e de seus entes queridos durante o processo do morrer.

Quando foi avaliado o tratamento instituído aos pacientes que morreram, observou-se que os pacientes internados na UTI receberam mais administração de drogas vasoativas (DVA) e, quando sofreram PCR, manobras de reanimação cardiorrespiratória lhes foram mais freqüentemente realizadas. Diversos são os motivos que podem explicar esse fato. A UTI é classicamente definida como uma unidade destinada a fornecer tratamento aos pacientes vítimas de patologias potencialmente reversíveis. Nessa unidade, é comum a prescrição de DVA para a otimização do suporte hemodinâmico ao paciente com instabilidade cardiocirculatória. Portanto, o uso de DVA é mais comum nessas unidades. Pode-se inferir que os pacientes internados nas enfermarias, que por ventura necessitem desse tipo de tratamento sejam encaminhados à UTI. Conseqüentemente, a maioria daqueles que morrem naquelas unidades são vítimas de doenças terminais o que explica a constatação, neste estudo, de que somente $5 \%$ dos pacientes internados nas enfermarias foram reanimados ao sofreram PCR. Podese deduzir que os óbitos nas enfermarias eram esperados na grande maioria dos casos. Essa observação torna-se relevante pela hipótese de que os profissionais envolvidos com o tratamento desses pacientes tenham aceitado a sua morte, fato pouco freqüente na sociedade atual $^{\mid 3}$. Idealmente, a RCP deveria ser iniciada quando o paciente tivesse oportunidade de uma recuperação que the permitisse uma existência confortável. Estudos mostram que a realidade difere desse ideal. Somente 40\% das RCR obtém sucesso imediato, em 25\% dos casos a reanimação apenas prolonga o processo do morrer e somente em $6 \%$ dos casos existe sobrevida sem seqüelas ${ }^{14}$.

\begin{tabular}{|c|c|c|}
\hline \multicolumn{3}{|c|}{$\begin{array}{c}\text { Tabela } 2 \text { - Principais terapias suspensas ou recusadas que } \\
\text { precederam os óbitos no HU/UFSC }\end{array}$} \\
\hline $\begin{array}{l}\text { Terapia } \\
\text { suspensa/recusada }\end{array}$ & $\begin{array}{l}\text { Óbitos ocorridos } \\
\text { na UTI (GI) }\end{array}$ & $\begin{array}{c}\text { Óbitos ocorridos } \\
\text { nas enfermarias (G2) }\end{array}$ \\
\hline $\begin{array}{l}\text { Drogas vasoativas } \\
\text { Noradrenalina } \\
\text { Dopamina } \\
\text { Dobutamina }\end{array}$ & $\begin{array}{c}21 \\
14 \\
8\end{array}$ & $\begin{array}{l}1 \\
2 \\
0\end{array}$ \\
\hline Antibióticos & 12 & 0 \\
\hline Métodos dialíticos & 8 & I \\
\hline Dieta enteral & 2 & 0 \\
\hline Novas medicações & 2 & 0 \\
\hline
\end{tabular}

A tecnologia moderna permite que as opções terapêuticas disponíveis nas UTIs mantenham vivos por um tempo indeterminado os pacientes sem possibilidade de recuperação. É imprescindível a lembrança de que prolongar o processo do morrer acarreta um maior sofrimento a todos aqueles envolvidos com esse processo e, conseqüentemente, fere os princípios bioéticos da beneficência e da nãomaleficiência ${ }^{13,15}$. Esse fato tem levado a necessidade de os médicos intensivistas restringirem a terapêutica dos seus enfermos vítimas de doença terminal. Atualmente, a maioria dos óbitos ocorridos em UTIs é precedida pela RST ${ }^{15-20}$. Inúmeros trabalhos ${ }^{17-20}$ que revisaram os óbitos de pacientes internados em UTIs da América do Norte e da Europa, concluíram que houve RST precedendo a morte entre 50\% e $77 \%$ dos óbitos. Moritz et al." realizaram, em 200 I, estudo na UTI do HU/UFSC e constataram que 32\% dos óbitos foram precedidos de RST. Neste estudo, houve aumento de sete pontos percentuais nos 
Tabela 3 - Motivos pelos quais os óbitos foram considerados evitáveis.

\begin{tabular}{|c|c|c|c|c|}
\hline \multirow[t]{2}{*}{$\begin{array}{l}\text { Causas de óbitos considerados } \\
\text { evitáveis }\end{array}$} & \multicolumn{2}{|c|}{$\begin{array}{l}\text { Obitos ocorridos } \\
\text { na UTI (GI) }\end{array}$} & \multicolumn{2}{|c|}{$\begin{array}{c}\text { Óbitos ocorridos } \\
\text { nas enfermarias (G2) }\end{array}$} \\
\hline & $\mathbf{N}$ & $\%$ & $\mathbf{N}$ & $\%$ \\
\hline $\begin{array}{l}\text { Complicaçoes não esperadas no pós-operatórí } \\
\text { Doençai infecciosafulminante em pacientes previamente hígidos } \\
\text { Diagnóstico tardio da patologia que levou à internaçãá } \\
\text { Procura tardia do sistema de saúde } \\
\text { Sem causa aparente (paciente levado ao serviço de verificação de óbitos) } \\
\text { Complicaçóestransoperatórias } \\
\text { Transporteintra-hospitalar } \\
\text { Outros relacionados a problemas externos ao hospital } \\
\text { Total }\end{array}$ & $\begin{array}{l}6 \\
5 \\
5 \\
1 \\
0 \\
0 \\
1 \\
1 \\
19\end{array}$ & $\begin{array}{c}31,6 \\
26,3 \\
26,3 \\
5,3 \\
0 \\
0 \\
5,26 \\
5,26 \\
100\end{array}$ & $\begin{array}{l}1 \\
0 \\
4 \\
1 \\
2 \\
1 \\
0 \\
1 \\
10\end{array}$ & $\begin{array}{l}10 \\
0 \\
40 \\
10 \\
20 \\
10 \\
0 \\
10 \\
100\end{array}$ \\
\hline
\end{tabular}

óbitos precedidos de RST em relação ao estudo de 2001. A maior conscientização por parte dos médicos e o melhor reconhecimento de que uma terapêutica possa ser fútil são os principais fatores envolvidos nessa diferença. Esse fato mostra a importância da discussão ampla sobre o tema morte e morrer. Embora no Brasil, discussões sobre a RST considerada fútil ou inútil tenham sido pouco estabelecidas do ponto de vista ético e legal, em países norte-americanos, esse tema tem sido amplamente debatido, já estando estabelecidas normas quanto ao direito legal da recusa de um tratamento por parte do paciente ou de seus familiares. Nesses países é definido que a meta das UTIs é prevenir o sofrimento desnecessário e a morte prematura, tratando de doenças reversíveis, durante um tempo apropriado. Sugere-se que exista um maior debate sobre o tema em questão, não apenas na área da saúde, mas em toda a sociedade $21-22$.

Felizmente, o debate sobre o tratamento médico no fim da vida tem sido estimulado nos últimos anos. Esse fato culminou com a elaboração, pelo Conselho Federal de Medicina ${ }^{23}$, da resolução |805/ 2006, que permite ao médico limitar ou suspender procedimentos e tratamentos que prolonguem a vida do doente, em fase terminal, de enfermidade grave e incurável, respeitada a vontade da pessoa ou de seu representante legal. Essa resolução foi indiscutivelmente uma importante vitória dos que lutam pela assistência integral daqueles que estão morrendo. É importante salientar que, também no meio jurídico, tem sido discutida a necessidade da suspensão de esforço terapêutico considerado fútil ou inútil. Esse ato tem suporte na Constituição, que reconhece a dignidade da pessoa humana como fundamento do Estado. Segundo Diaulas Costa Ribeiro ${ }^{24}$, a omissão de tratamentos médicos, a pedido do doente não suicida, não constitui crime. 0 médico, desde que não pertença a equipe de transplante, pode participar da tomada de decisão de suspender esforço terapêutico (nutrição, hidratação, ventilação) considerado fútil.

No trabalho de Moritz et al.", foi demonstrado que os vasopressores e os antibióticos foram as principais terapias recusadas. No atual estudo as drogas vasoativas e os antimicrobianos também foram as principais terapias recusadas ou suspensas, que precederam os óbitos na UTI. Decisões semelhantes foram tomadas tanto por médicos europeus quanto por norte-americanos ${ }^{20,22,25}$. Outros estudos mostraram resultados diferentes no que concerne a qual terapia é mais freqüentemente recusada ou suspensa. $\mathrm{O}$ estudo de McLean et al. ${ }^{25}$ constatou que a terapêutica mais freqüentemente retirada foi o suporte ventilatório sendo mantidas a sedação e a analgesia. Na Finlândia, Hinkla et al. ${ }^{26}$ observaram os fatores que afetam os médicos quanto às decisões de recusa ou suspensão de tratamentos em vítimas de doença cancerosa em fase final e constataram que os tratamentos mais recusados foram a transfusão sangüínea e a profilaxia da trombose. Moritz et al. ${ }^{27}$, em um estudo que avaliou a atitude dos médicos intensivistas brasileiros diante da RST, mostraram que a sedação e a analgesia foram as intervenções menos recusadas ou suspensas e que os métodos dialíticos constituíram a terapêutica mais comumente recusada ou suspensa. No mesmo trabalho, o suporte ventilatório foi recusado em quase $25 \%$ das vezes e, se já instituído, foi retirado por $4 \%$ dos participantes, tendo sido a intervenção menos suspensa. Outro trabaIho brasileiro, realizado na Bahia, constatou que o limite terapêutico precedeu $60 \%$ dos óbitos na UTI, que é mais comum a recusa de novos tratamentos do que a suspensão dos mesmos e que a nutriçãa, a sedação e a analgesia são terapias mantidas até a morte ${ }^{27}$.

Neste estudo, a média da idade dos pacientes, cuja terapia foi suspensa ou recusada, foi de 58 anos enquanto um estudo canadense apontou uma média de 65 anos. ${ }^{15}$ Quando foram comparadas as médias de idade entre os pacientes que faleceram sendo mantida terapia plena, não houve diferença entre os deste trabalho e do estudo canadense. ${ }^{15}$ Segundo o estudo canadense, a RST foi mais incidente nos pacientes mais velhos. Na UTI do HU/UFSC, a idade dos pacientes para os quais foi mantida a medicação plena foi semelhante à daqueles cuja terapia foi recusada ou suspensa.

Outro fato avaliado foi o período do dia em que os óbitos ocorreram, já que esse fato pode estar indiretamente relacionado com a qualidade do atendimento prestado. Toscani et al. ${ }^{4}$ relataram que há maior número de óbitos durante período diurno nos hospitais italianos. Neste trabalho, não foi encontrada diferença quanto ao período de ocorrência das mortes no HU/UFSC.

Neste trabalho, foi observado que nas enfermarias houve predominância da ocorrência de óbitos esperados e não-evitáveis. Na UTI, os óbitos considerados evitáveis e não esperados foram mais freqüentes, fato esperado, pois nesse setor são internados os pacientes mais agudamente enfermos e com quadro potencialmente reversível e por 
esse motivo há uma maior expectativa quanto a melhora do seu quadro clínico. Resultados semelhantes foram apontados por Hayward et al. ${ }^{29}$, que avaliaram óbitos em hospitais norte-americanos, e concluíram que $6 \%$ desses óbitos eram provavelmente evitáveis.

Descreve-se a seguir os motivos que levaram os membros da $\mathrm{COH}$ a classificarem os óbitos como evitáveis. As principais causas consideradas evitáveis foram as mortes que ocorreram no pós-operatório. Deve-se lembrar que complicações, inclusive a morte, são inerentes a qualquer ato cirúrgico. Essas complicações, embora possam ser consideradas evitáveis, são aceitáveis quando dentro das taxas bem estabelecidas na literatura médica. As mortes decorrentes de doença infecciosa fulminante foram também enquadradas neste trabalho como evitáveis, sendo esse fato devido a diversos fatores. Foi considerado que, em alguns casos, se a procura do paciente por assistência médica fosse mais precoce, poderia ter havido outro desfecho. Em outros casos a própria evolução da doença foi fulminante e, embora o óbito não tenha sido esperado, seguiu o ciclo natural das doenças extremamente graves, nas quais existe pouca influência do tratamento médico. Outro fato anotado pelos membros da $\mathrm{COH}$ foi o de que, em dois enfermos, o diagnóstico possa ter sido retardado por problemas inerentes ao quadro clínico dos mesmos. Sobre o óbito ocorrido após o transporte intra-hospitalar, também são descritas na literatura as complicações relacionadas ao transporte, tanto intra quanto interhospitalar. No caso em questão houve uma complicação, relatada na literatura, em paciente com quadro extremamente grave e com prognóstico reservado. Todos os casos ora relatados foram considerados pelos membros da $\mathrm{COH}$ como evitáveis. Entretanto, não foi constatado nenhum indício de erro institucional que tivesse influído diretamente no evento fatal. Hayward et al. ${ }^{29}$ sugerem que devem ser sempre avaliados com atenção os dados referentes aos óbitos considerados como evitáveis. Após o lançamento de um relatório do Instituto Americano de Medicina, que estimou os erros médicos como a 5 a causa de morte nos EUA, correspondendo à cerca de 90.000 mortes/ano, esses autores realizaram um estudo que avaliou os métodos utilizados para a classificação dos óbitos em evitáveis e apontaram que, apesar de diversas classificações quanto o grau de evitabilidade, os resultados sempre eram semelhantes entre os vários estudos realizados. Os autores concluíram que havia uma baixa probabilidade de o fato classificado pelo revisor como erro médico ser a real causa da morte dos pacientes cujo óbito foi classificado como evitável; que as avaliações feitas pelos revisores eram pouco confiáveis e geralmente possuíam vieses; e que apesar de a morte desses pacientes poder ser evitada, freqüentemente o prognóstico em curto prazo da pessoa que morreu foi julgado como muito limitado. Neste trabalho, o fato de a análise dos membros da $\mathrm{COH}$ ter sido realizada de forma subjetiva e retrospectiva pode ter levado a um viés de interpretação. Entretanto, essa comissão apresentou conclusões semelhantes no que concerne ao prognóstico dos pacientes cujo óbito foi considerado como evitável.

Após a avaliação dos dados encontrados, pode-se concluir que as características clínicas e terapêuticas dos pacientes que morreram nas enfermarias do HU/UFSC foram diferentes das características daqueles que morreram na UTI. Os pacientes que morreram na UTI eram mais jovens e receberam mais DVA. Nessa unidade, os óbitos foram mais freqüentemente precedidos da RST. A RCR foi realizada em somente
5\% das PCR nas enfermarias, onde foi constatada a ordem para que não fosse realizada RCR em $48 \%$ dos prontuários. Treze por cento dos óbitos foram considerados não- esperados e $10 \%$ evitáveisl. Não foi constatado erro profissional ou institucional nos óbitos avaliados.

\section{Conflito de interesse: não há}

\section{SUMMARY}

\section{Evaluation of deaths occurred at the University Hospl- TAL (HU/UFSC)}

OBIECTNE. To evaluate the deaths which occurred at the HU/UFSC. To compare the profile of patients who died in the wards with that of patients who died in the ICU. To classify deaths which were expected ornot, and avoidable or not. To verify how often with holding or withdrawing (WW) therapy preceded death.

MetHODs. Archives of the Hospital Death Commission (HDC) were analyzed. The clinical and demographic records were retrieved from the HDC data bank. Deaths were classified by the HDC as expected ornotand avoidable ornot.

RESULTS. Data from 326 dead persons over 14 years of age were analyzed. One hundred and twenty eight deaths occurred in the ICU(GI) and 198 in the wards (G2). WW therapy preceded $38.2 \%$ of deaths in $G$ I and $2 \%$ in $G 2(p<0.001)$. The main WW therapies were vasoactive drugs and antibiotics. Almost $20 \%$ of deaths were unexpected/avoidable in G . In $G 26.5 \%$ were considered unexpected and $5 \%$ avoidable $(p<0.005)$. Patients in GI were younger and mostly male $(p<0.005)$. Do-notresuscitate orders were registered in $48.4 \%$ of patients' medical charts in $G 2$ and $6.3 \%$ in $G I(p<0.001)$. Cardiopulmonary resuscitation was performed in $23.4 \%$ of patients in $G 1$ and in $5.5 \%$ in $G 2(p<0.001)$.

CONCLUSION. In GI, patients were younger and deaths were more frequently preceded by WW. In G2, half of the patients had do-notresuscitate order registered in their medical charts. In only a few patients were deaths considered unexpected or avoidable. No evidentprofessional or institutional error was identified. [Rev Assoc Med Bras 2008; 54(5): 390-5]

KEY wORDS: Dead. Ethics. Futility. Withdrawal treatment.

\section{REFERÊNCIAS}

I. World Health Organization (WHO). [cited 2006 apr]. Available from: http://www.who.org/.

2. Goodlin SJ, Winzelberg GS, Teno JM, Whedon M, Lynn J. Death in the hospital. Arch Intern Med. I998; I 58(I4): I 570-72.

3. Rosen G. A history of public health. Baltimore: Johns Hopkins University Press, 1993.

4. Toscani F, Di Giulio P, Brunelli C, Miccinesi G, Laquintana D. How people die in hospital general wards: a descriptive study. J Pain Symptom Manage. 2005;30(I):33-40.

5. Jacobs LG, Bonuck K, Burton W, Mulvihill M. Hospital care at the end of life: an institutional assessment. J Pain Symptom Manage. 2002;24(3):29I-8.

6. Fins JJ, Miller FG, Acres CA, Bacchetta MB, Huzzard LL, Rapkin BD. End of life decision making in the hospital: current practice and future prospects. J Pain Symptom Manage. 1999;17(1):6-10.

7. Heide Av, Deliens L, Faisst K, Nilstun T, Norup M, Paci E, et al. End-oflife decision-making in six European countries: descriptive study. Lancet. 2003;36I (9354):345-50. 
8. Seymour JE. Negotiating natural death in intensive care. Soc Sci Med. 2000; $51:$ | $24 \mid-52$.

9. Datasus. Departamento de Informação e Informática do SUS. Ministério da Saúde. [citado 25 abr 2006]. Disponível em http://www.datasus.gov.br/.

10. Moritz, RD. O efeito da informação sobre o comportamento dos profissionais de saúde diante da morte [tese]. Florianópolis: Universidade Federal de Santa Catarina; 2002

I I. Moritz RD, Pamplona F. Avaliação da recusa ou suspensão do tratamento considerados fúteis ou inúteis. Rev Bras Ter Intensiva. 2003; I 5( I):40-5.

12. Hall RI, Rocker GM. End-of-Life Care in the ICU: treatments provided when life support was or was not withdrawn. Chest. 2000; I | 8(5): | 424-30.

13. Moritz RD. A morte e o morrer nas Unidades de Terapia Intensiva. In: David CM, organizador. Medicina intensiva. Rio de Janeiro: Revinter; 2003. p.68-78.

14. 2005 American Heart Association Guidelines for cardiopulmonary resuscitation and emergency cardiovascular car: Part 7.2: management of cardiac arrest circulation. Circulation. 2005; I I 2(4):IV-58-66.

15. Winter B, Cohen S. ABC of intensive care: with-drawal of treatment. $\mathrm{Br}$ Med J. 1999;319(7206):306-8.

16. Sprung CL, Eidelman LA, Reuven R, Geber D, Jakobson DJ. Communication of end of life decisions in the ICU. Crit Care Med. 2000;8(Suppl 12): A35.

17. Smedira NG, Evans BH, Grais LE, Cohen NH, Cooke M, Schecter WP, et al. Withholding and withdrawal of life support from the critically ill. N Engl J Med. 1990;322(5):309- I 5.

18. Ferrand E, Robert R, Ingrand P, Lemaire F. Withholding and withdrawal of life support in intensive-care units in France: a prospective survey. French LATAREA Group. Lancet. 2001 ;357(9249):9-14.

19. Esteban A, Gordo F, Solsona JF, Alia I, Caballero J. Withdrawing and withholding life support in the intensive care unit: a Spanish prospective multi-centre observational study. Intens Care Med. $2001 ; 27($ I I ): I 744-9.

20. Keenan SP, Bushe KD, Chen LM, McCarthy L, Inman KJ, Sibbald WJ. A retrospective review of a large cohort of patients undergoing the process of withholding or withdrawal of life support. Crit Care Med. | 997;25(8): | 324-3|.

21. Singer PA. Barker G; Bowman KW, Harrison C, Kernerman P, Kopelow J, et al. Hospital policy on appropriate use of life-sustaining treatment. Crit Care Med. $2001 ; 29(1)$ : | 87-91

22. Vincent JL. Ethical issues in critical care medicine: United States and European views and differences. Intensive Care World. 1996; 13(4): | 42-4

23. Conselho Federal Medicina. Bioética. 2005; | 3(2): I 28-9.

24. Ribeiro DC. A eternal busca da imortalidade humana: a terminalidade da vida e a autonomia. Bioética. 2005; | 3(2): I | 2-20.

25. McLean RF, Tarshis J, Mazer CD, Szalai JP. Death in two Canadian intensive care units: institutional difference and changes over time. Crit Care Med. 2000;28(1): 100-3.

26. Hinkla H, Kosunen E, Metsanoja R, Lammi UK, Kellokumpu-Lehtinen P. Factors affecting physicians' decisions to forgo life-sustaining treatments in terminal care. J Med Ethics. 2002;28(2): I09-14.

27. Moritz RD, Costa AD, Mattos JD, Machado FO. O comportamento do médico intensivista brasileiro diante da decisão de recusar ou suspender um tratamento. Rev Bras Ter Intensiva. 200 |; |3(|3):2 |-8.

28. Bitencourt AGV, Dantas MP, Neves FBC,Almeida AM, Melo RMV, Albuquerque LC, et al. Condutas de limitação terapêutica em pacientes internados em Unidade de Terapia Intensiva. Rev Bras Ter Intensiva. 2007; | 9(2): | 37-43.

29. Hayward RA, Hofer TP. Estimating hospital deaths due to medical errors: preventability Is in the eye of the reviewer. JAMA. 200I; 286(4):415-20.
Artigo recebido: 06/09/06 Aceito para publicação: 10/04/08 